\title{
Correction to: Comparison of the effects of weight loss from a high-protein versus standard-protein energy-restricted diet on strength and aerobic capacity in overweight and obese men
}

\author{
Thomas P. Wycherley ${ }^{1}$. Jonathan D. Buckley ${ }^{1} \cdot$ Manny Noakes $^{2} \cdot$ Peter M. Clifton $^{3} \cdot$ Grant D. Brinkworth $^{2}$
}

Published online: 10 September 2020

(c) Springer-Verlag GmbH Germany, part of Springer Nature 2020

\section{Correction to: Eur J Nutr (2013) 52:317-325}

https://doi.org/10.1007/s00394-012-0338-0

The original version of this article unfortunately contained a mistake. In the section "Experimental protocol", in the last sentence of the second paragraph, there is a typo in the trial registration number.

Two numbers were omitted by accident and instead of ACTR No: 126000002583 , the correct number should be reported as ACTRN12606000002583.

The original article can be found online at https://doi.org/10.1007/ s00394-012-0338-0.

Grant D. Brinkworth grant.brinkworth@csiro.au

1 Division of Health Sciences, Sansom Institute for Health Research, University of South Australia, Adelaide, Australia

2 Preventative Health Flagship, Commonwealth Scientific and Industrial Research Organisation, Food and Nutritional Sciences, PO Box 10041 BC, Adelaide 5000, Australia

3 Baker IDI Heart and Diabetes Institute, Adelaide, Australia 